\title{
A simple, enaminone-based approach to some bicyclic pyridazinium tetrafluoroborates
}

\author{
František Josefík $^{1}$, Markéta Svobodová ${ }^{1}$, Valerio Bertolasi ${ }^{2}$ \\ and Petr Šimůnek ${ }^{* 1}$
}

\section{Full Research Paper}

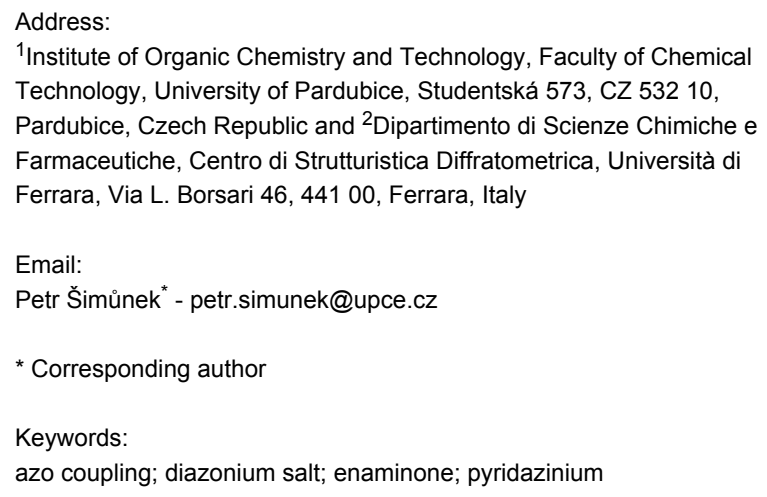

${ }^{1}$ Institute of Organic Chemistry and Technology, Faculty of Chemical Technology, University of Pardubice, Studentská 573, CZ 532 10, Pardubice, Czech Republic and ${ }^{2}$ Dipartimento di Scienze Chimiche e Farmaceutiche, Centro di Strutturistica Diffratometrica, Università di Ferrara, Via L. Borsari 46, 44100 , Ferrara, Italy

Email:

Petr Šimůnek* - petr.simunek@upce.cz

* Corresponding author

Keywords:

azo coupling; diazonium salt; enaminone; pyridazinium

Beilstein J. Org. Chem. 2013, 9, 1463-1471. doi:10.3762/bjoc.9.166

Received: 21 March 2013

Accepted: 28 June 2013

Published: 23 July 2013

Associate Editor: V. M. Dong

(C) 2013 Josefík et al; licensee Beilstein-Institut. License and terms: see end of document.

\begin{abstract}
Easily obtainable cyclic enaminones (piperidin-2-ylidenealkanones) can be transformed into substituted bicyclic pyridazinium tetrafluoroborates upon treatment with corresponding diazonium salts. The transformation can be performed either in a one-pot way or in a two-step process with the isolation of single azo-coupled enaminone as the intermediate. The former method is superior. Under the optimized conditions, a number of pyridazinium salts substituted with both electron-donating and electron-withdrawing substituents was easily synthesized. A mechanism of the formation of the pyridazinium salts is suggested. A partial drawback is the possibility of the formation of a mixture of products when using a different diazonium salt in each step due to a reversibility of the azo coupling. This can be suppressed by using a more reactive diazonium salt before a less reactive one.
\end{abstract}

\section{Introduction}

As heterocyclic compounds play a very important role in everyday life, e.g., as pharmaceuticals, agrochemicals, dyes, etc. (for many monographies or textbooks on this topic see, e.g. [1]), searching for new heterocyclic systems or novel methods for the synthesis of the existing ones represents a very important part of organic chemistry. Enaminones, due to their ability to react with both electrophiles and nucleophiles, are versatile synthons, and not only in heterocyclic chemistry (for many reviews see, e.g., [2-6]). During the past several years we have dealt with the reaction of various enaminones with diazonium salts and established a number of methods for the construction of some important or unusual heterocyclic systems [7-15], including a simple protocol leading from enaminones $\mathbf{1}$ to 6-substituted 4-amino-5-aryldiazenyl-1-arylpyridazinium salts 2 $[14,15]$. The procedure consists of the reaction of the corresponding enaminones and two equivalents of diazonium tetra- 


$$
\begin{aligned}
& \text { (n) } \\
& \mathrm{Z}=\mathrm{BF}_{4}^{-}, \mathrm{PF}_{6}{ }^{-} \\
& \mathrm{Y}=2,4-(\mathrm{OMe})_{2} \mathrm{Ph}, \mathrm{Me}, 4-\mathrm{OMePh}, 4-\mathrm{MePh}
\end{aligned}
$$

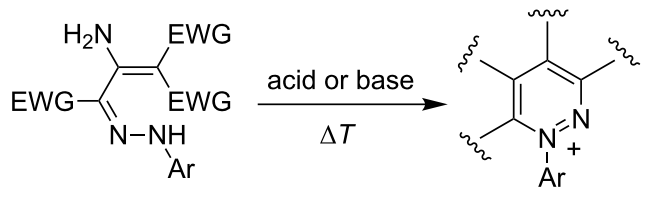

Scheme 1: Syntheses of 1-arylpyridazinium salts.

fluoroborates or hexafluorophosphates with the later giving better yields and applicability (Scheme 1, top).

It extends the existing procedure [16-24] for the construction of the 1-arylpyridazinium scaffold based on acid- or basecatalyzed cyclization of the corresponding hydrazones (Scheme 1, bottom). Apart from this, reactions of enaminones with diazonium salts giving substituted pyridazines are also described [25-28]. Our method does not require any additive, and the transformation from $\mathbf{1}$ to $\mathbf{2}$ is performed as a one-pot procedure. Different substrates are used and different and novel pyridazinium patterns are built under mild conditions [14,15].

The above-mentioned method [14,15] (Scheme 1, top) is, however, limited to electron-donating or slightly electronwithdrawing $(-\mathrm{Cl})$ substituents on diazonium salts. Only the enaminones having a $\mathrm{C}=\mathrm{C}(\mathrm{NHR})-\mathrm{CH}_{3}$ fragment were successfully applied. In this study we decided to further examine the reaction of enaminones with diazonium tetrafluoroborates in

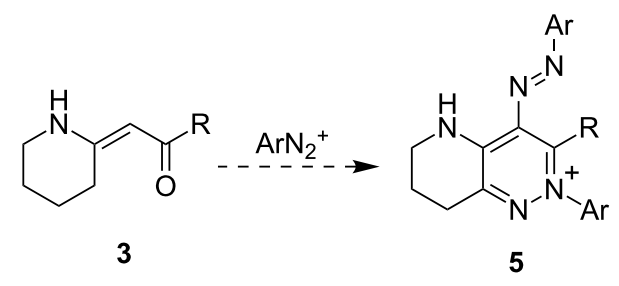

Scheme 2: Suggested transformation of the cyclic enaminones into the corresponding bicyclic pyridazinium salts.

order to extend the applicability of the method. As the substrates, we have chosen the exocyclic enaminones $\mathbf{3}$, which would gain access to bicyclic pyridazinium salts 5 (Scheme 2).

\section{Results and Discussion}

Enaminones 3 were prepared as previously reported [12] (Scheme 3). The last step of the synthesis is the deacetylation of 7 by sodium in ethanol. In the case of substrate 3a the deacetylation spontaneously takes place during the 2 nd step.

The reaction of the enaminone 3a with two equivalents of 4-methylbenzenediazonium tetrafluoroborate under the same conditions as described in [8] (i.e., DCM, rt, 2 equiv of diazonium salt, 6 equiv of sodium acetate) afforded the corresponding pyridazinium salt 5a in $36 \%$ yield. The same procedure applied to the benzoylacetone derivative $\mathbf{3 b}$ gave even lower yield (19\%) of the salt $\mathbf{5 g}$.

The cause of the low yields probably lies in the method of performing the reaction. The solid diazonium salt, added in one portion, could partially decompose before being able to react causing both lowering of the yield and contamination of the reaction mixture with the decomposition products. Therefore, the first attempt to improve the yields ( $m e t h o d A)$ consisted in portionwise addition of the diazonium salt. The second portion was added after the first one had been fully consumed (tested by chromotropic acid). Using this method, we were able to prepare also mixed pyridazinium salts from two different diazonium salts (Scheme $4, \mathrm{Ar}^{1} \neq \mathrm{Ar}^{2}$ ). However, the yields were still, at best, moderate (Table 1).

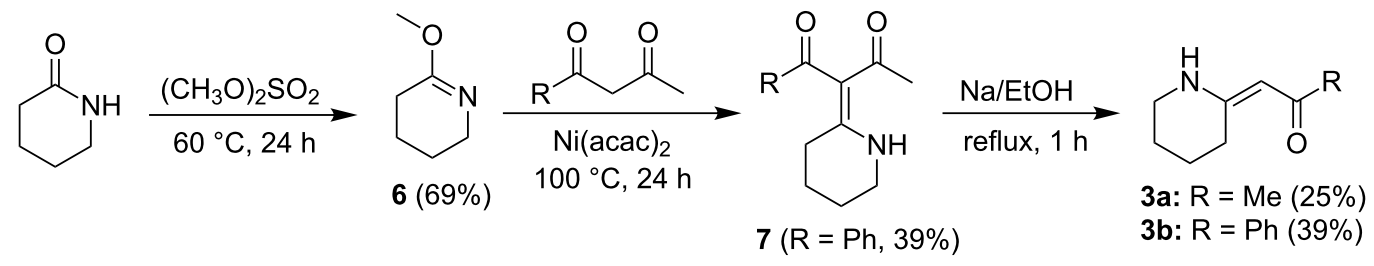




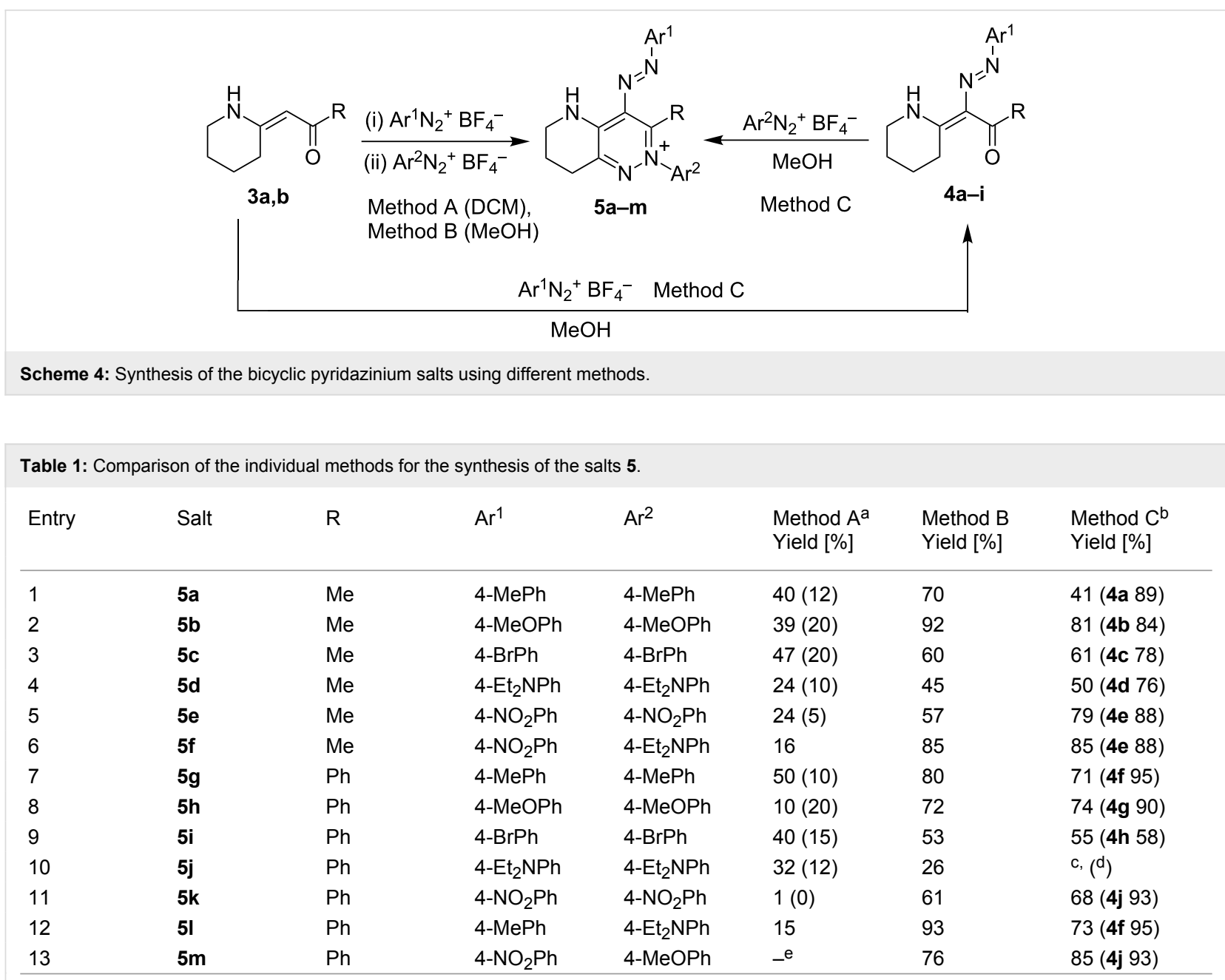

aYields for 6 equiv of AcONa are in parentheses. bYield for the 2 nd step. Yields for the 1 st step (product 4 ) are in parentheses. ${ }^{\mathrm{C}}$ Failed. ${ }^{\mathrm{d} P r o d u c t} \mathbf{4} \mathbf{i}$ is too unstable to be isolated and was used directly in the next reaction step. ${ }^{e}$ Not performed.

Method A was then modified. To achieve better homogeneity of the reaction mixture, a solution of the diazonium salt in methanol was used instead of the solid salt (method B). This modification led to a substantial increase of the yields (Table 1).

Further modification (method C) comprises step-by-step implementation of the methodology B. After the consumption of the first equivalent of the diazonium salt the reaction mixture was worked-up and the product was isolated and characterized by means of ${ }^{1} \mathrm{H}$ and ${ }^{13} \mathrm{C}$ NMR in solution and elemental analysis or HRMS. The isolated intermediates 4 were subjected to the reaction with another equivalent of the diazonium salt. The same products as in the case of the one-pot procedures (methods A,B) were isolated (Scheme 4). For comparison of the stepwise procedure (method $\mathrm{C}$ ) with the other ones see Table 1. The methodology failed only in the case of compound $4 \mathbf{i}$ (Table 1 , entry 10), which was too unstable and decomposed upon an attempt of its isolation.
The pyridazinium salts prepared were characterized by means of ${ }^{1} \mathrm{H}$ and ${ }^{13} \mathrm{C}$ NMR spectroscopy and elemental analysis or HRMS (see Experimental and Supporting Information File 1). Some of them were characterized also by means of X-ray analysis (see below).

The mechanism of the azo coupling of primary and secondary enaminones was studied in [29]. The formation of compounds 4 can be assumed to proceed in an analogous way. A possible explanation of the formation of the pyridazinium salts $\mathbf{5}$ from the intermediates 4 is shown in Scheme 5 .

Compound 4, formed either in situ (methods A,B) or in a separate experiment (method $\mathrm{C}$ ) can exist in equilibrium with its enol form. It reacts with another equivalent of the diazonium salt to form the product of double azo coupling Im (Scheme 5). We have observed the formation of similar compounds upon azo coupling of some enaminones [11,30,31]. Fluoroboric acid, 


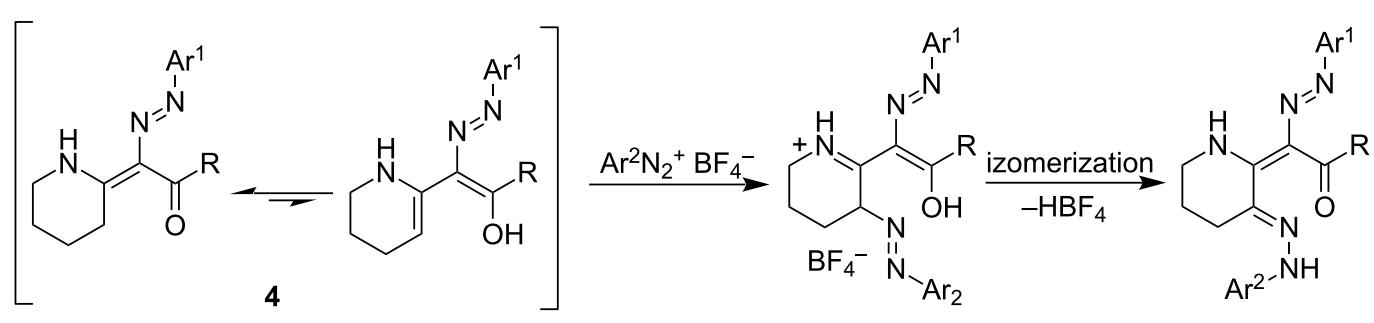

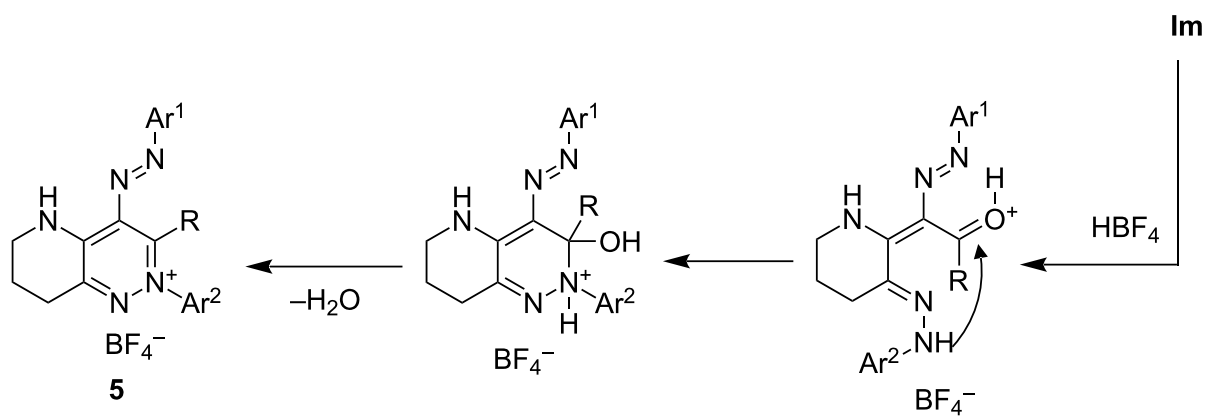

Scheme 5: Possible mechanism of the formation of the pyridazinium salts 5 .

liberated during the formation of $\mathbf{I m}$, is not captured by the base (as no equivalent of sodium acetate is used in the 2nd step) and could catalyze an intramolecular attack of hydrazone $\mathrm{NH}$ nitrogen to the carbonyl group. After a subsequent loss of water, the molecule of pyridazinium salt $\mathbf{5}$ is formed. This hypothesis is supported by the fact that the use of an excess of sodium acetate led to significantly lower yields (for comparison see Table 1, method A). However, the above-mentioned scheme is only a speculation (as the intermediate Im has never been isolated) based on the observations made on similar reactions and on the knowledge of structures of the starting compounds and the products.

An attempt at preparation of 4-(4-methoxyphenyldiazenyl)-2(4-nitrophenyl)-3-phenyl 5,6,7,8-tetrahydropyrido[3,2-c]pyridazin-2-ium tetrafluoroborate (5n) failed. A mixture of compounds 5k $+\mathbf{5 m}$ (approx. 1:2) was obtained instead. Crystallization of the mixture gave a mixed crystal $(\mathbf{5 k}+\mathbf{5 m}$, for discussion of its structure see below). A possible explanation for this lies in an exchange of the diazonium ions (Scheme 6).

The mechanism of the exchange is described in [32]. Its application to the reaction of $\mathbf{4 g}$ with 4-nitrobenzenediazonium ion (Scheme 6) can explain the formation of the mixture of pyridazinium salts $\mathbf{5 k}+\mathbf{5 m}$ : $\mathbf{4 g}$ can react with another molecule of the diazonium salt either to give the bishydrazone intermediate $\mathbf{I m}$ and subsequently the pyridazinium salt $\mathbf{5 n}$ (in the sense of Scheme 5) or it can undergo an ipso attack to form the intermediate Ip, consisting of 4-methoxy and 4-nitrophenyldiazenyl groups. The ipso attack is faster but reversible, whereas the formation of Im followed by the cyclization to the pyridazinium ion $\mathbf{5}$ is slower but irreversible. The less electrophilic benzenediazonium ion (4-methoxy) is preferentially eliminated from Ip to give $4 \mathbf{j}$ (the product of the exchange of the diazenyl groups). $4 \mathbf{j}$ can further react either with another equivalent of 4-nitrobenzenediazonium (to give 5k) or with 4-methoxybenzenediazonium (formed by cleavage from the Ip intermediate) to give $\mathbf{5 m}$ (both in the sense of Scheme 5). Compound $\mathbf{5 n}$ is not formed as it requires the cleavage of the more electrophilic benzenediazonium ion (4-nitro) from Ip (disfavored).

The above-mentioned appears to be a drawback of the methodology: the more reactive diazonium salt should be used before the less reactive one otherwise a mixture of products can arise.

Similar results were obtained on reaction of $\mathbf{4 b}$ with an equivalent of 4-bromobenzenediazonium tetrafluoroborate: a mixture of products was obtained. Attempts to separate the components of such mixtures failed, probably due to the very similar properties of the pyridazinium salts formed.

It should be emphasized that the above-mentioned suggestions on the mechanism are only suppositions based on the structures of the isolated compounds and reactants as well as the results obtained in similar reactions.

The structures of the compounds $\mathbf{5 a}, \mathbf{b}, \mathbf{d}, \mathbf{f}, \mathbf{g}, \mathbf{j}, \mathbf{l}, \mathbf{m}$ were also solved by using X-ray diffractometry. ORTEP [33] views of the compounds $\mathbf{5 f}$ and $\mathbf{5 l}$ are shown in Figure 1 and Figure 2, the others are given in Supporting Information File 1. Almost all the structures display some disorder. Structures $\mathbf{5 d}, \mathbf{5 f}, \mathbf{5 j}$ and $\mathbf{5 l}$ show disorder in the $\mathrm{C} 3-\mathrm{C} 7, \mathrm{~N} 3$ six-membered rings and the 


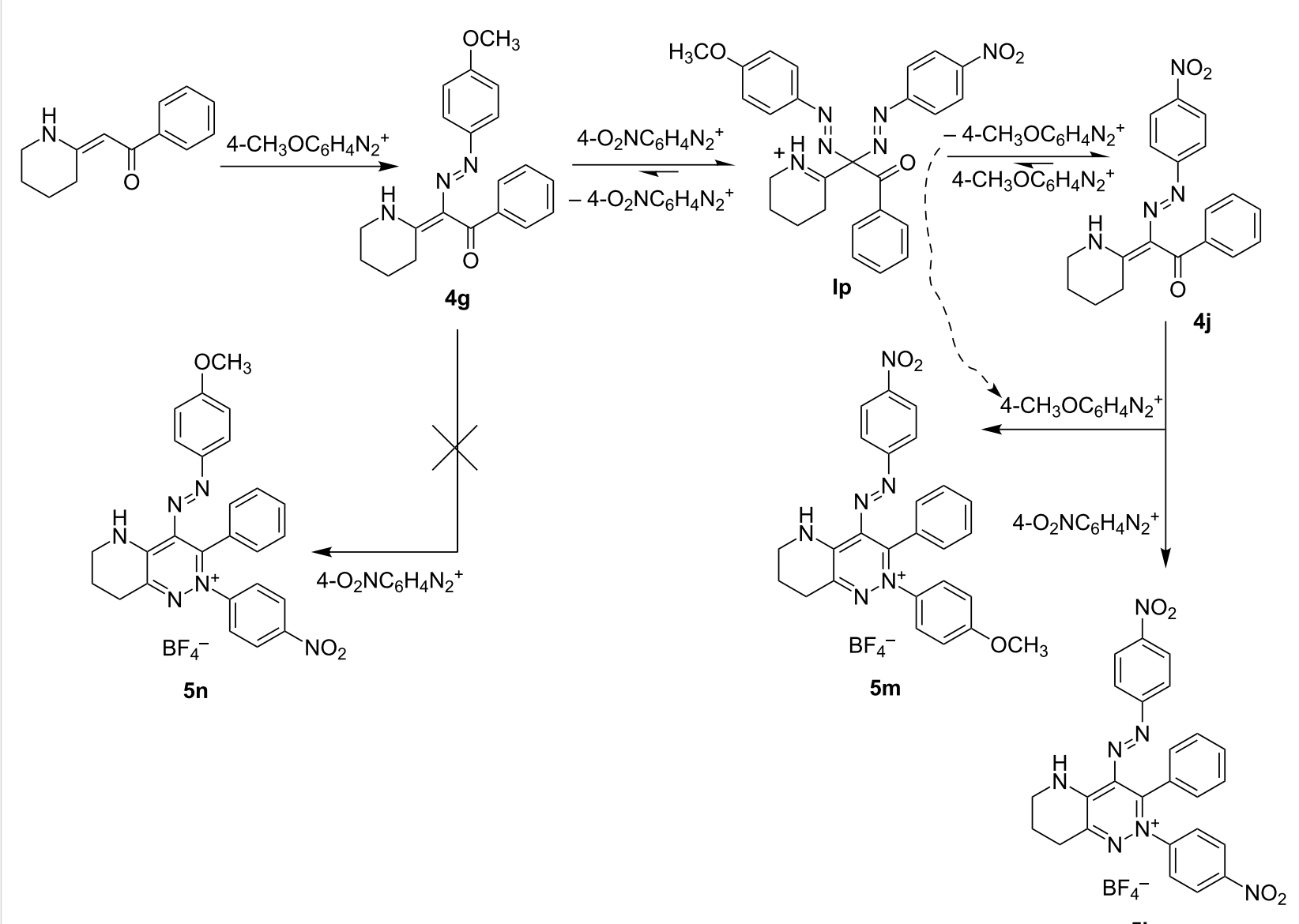

$5 \mathbf{k}$

Scheme 6: An attempt at synthesis of $5 \mathrm{n}$ and possible explanation of the failure.

$\mathrm{C} \mathrm{H}_{2}$ moieties were refined over two sites. All the $\mathrm{BF}_{4}{ }^{-}$anions exhibit high temperature factors; in $\mathbf{5} \mathbf{d}$ and $\mathbf{5 l}$ the fluorine atoms were refined over two split sites. In $\mathbf{5 m}$ the asymmetric unit is built up by two cations, which differ only in the conformation of the $\mathrm{O}-\mathrm{CH}_{3}$ moiety, and two $\mathrm{BF}_{4}{ }^{-}$anions. Also in $\mathbf{5 k}+\mathbf{5 m}$ the asymmetric unit is built up by two cations, but while the structure of the cation A did not present any problems during the refinement, the cation $\mathrm{B}$ revealed a structure with two superimposed substituents, $-\mathrm{OCH}_{3}$ and $-\mathrm{NO}_{2}$, in para position at $\mathrm{C} 20 \mathrm{~b}-\mathrm{C} 25 \mathrm{~b}$ phenyl ring. The two different substituents were refined independently with occupancies of 0.5 each.

The crystal data are given in Supporting Information File 1 (Table S1). A selection of bond distances and angles and the intramolecular hydrogen bond parameters are also reported in Supporting Information File 1 (Table S2 and Table S3).

\section{Conclusion}

We have developed an improved simple methodology for the construction of bicyclic pyridazinium tetrafluoroborates. The heterogeneous variant (method A) suffers from low yields, probably due to a partial decomposition of the diazonium salt during the reaction. An implementation of homogeneous reaction conditions using a methanolic solution of the corresponding diazonium tetrafluoroborates led to a substantial increase of both yields and the scope of the existing procedure. Two variations of the homogeneous procedure were tested:

1. A two-step procedure (method $\mathrm{C})$ with the isolation and characterization of the intermediates $\mathbf{4}$ followed by their reaction with another equivalent of the diazonium salt.

2. A one-pot procedure (method B) with the addition of another equivalent of the diazonium salt into the reaction mixture directly after the consumption of the first equivalent without the isolation of the intermediate 4 .

The single-stage protocol (method B) is superior to the other ones as it gives comparable or better yields without the need to isolate the intermediate 4 .

Pyridazinium salts 5 arise from azo-coupled enaminones 4 probably via the products of double azo coupling (Im) through 


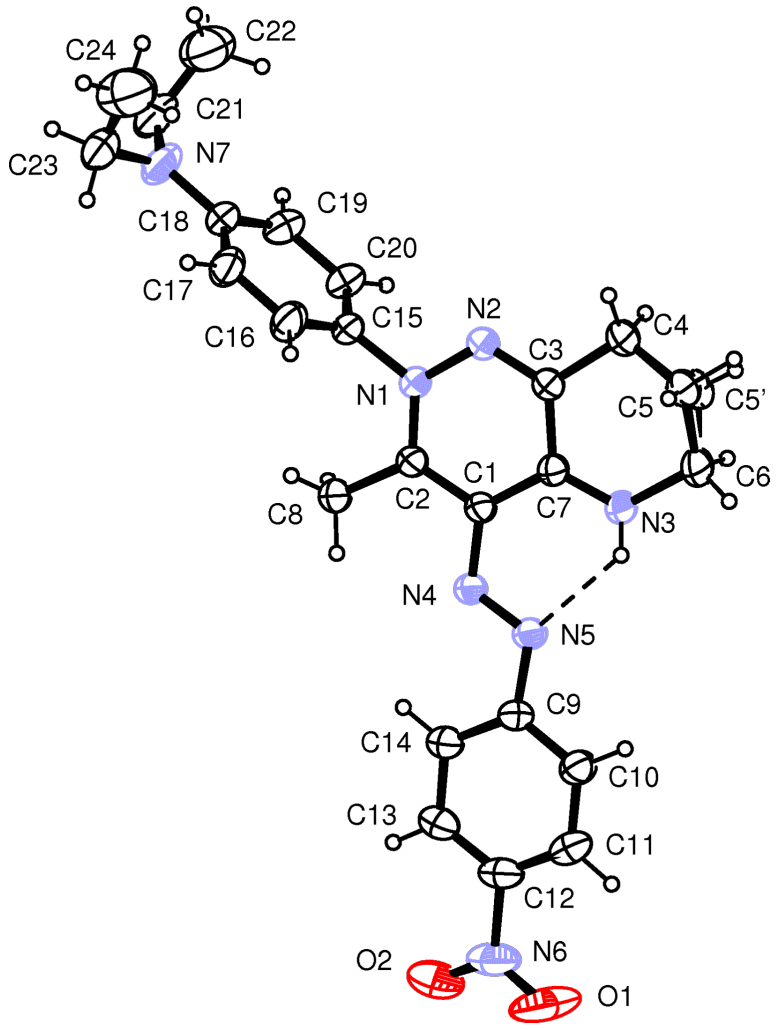

Figure 1: ORTEP view of the cation of compound $\mathbf{5 f}$ showing the thermal ellipsoids at $30 \%$ probability level. Both the disordered $\mathrm{C}_{5} \mathrm{H}_{2}$ and $\mathrm{C}^{\prime} \mathrm{H}_{2}$ moieties are displayed.

an intramolecular nucleophilic addition followed by the loss of water. The statement is, however, based only on the structures of the reactants and products and on the comparison with similar reactions.

A drawback of the method is the fact that azo coupling is a reversible reaction. The more reactive diazonium salt can replace the less reactive one to give a mixture of products. The ideal combination is to use the more reactive diazonium salt followed by the less reactive one, as the diazonium exchange is suppressed here.

\section{Experimental}

All the solvents and reagents were purchased from commercial suppliers and were used without further purification. Diazonium tetrafluoroborates were prepared according to an ordinary procedure (diazotization using cold $\mathrm{NaNO}_{2} / \mathrm{HCl}$ with subsequent precipitation, from the filtered solution of the diazonium chloride, by aqueous sodium tetrafluoroborate). Precipitated diazonium tetrafluoroborates were dried in vacuo in a desiccator and stored in a refrigerator.

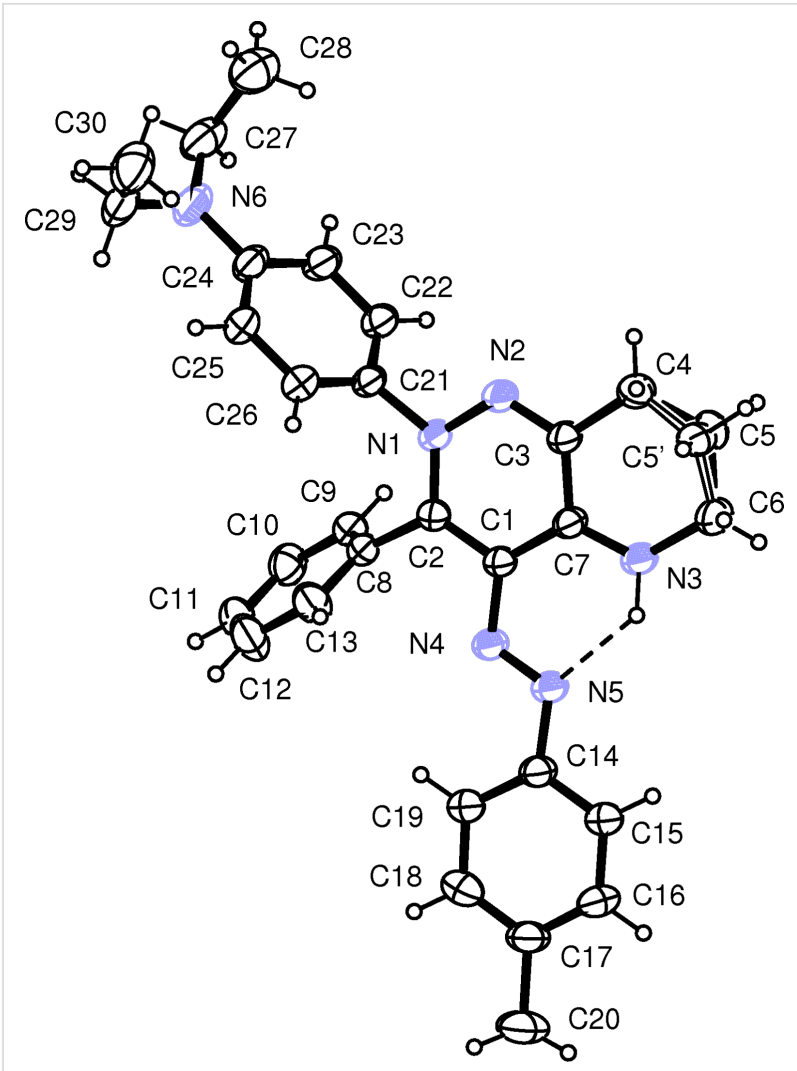

Figure 2: ORTEP view of the cation of compound $\mathbf{5 l}$ showing the thermal ellipsoids at $30 \%$ probability level. Both the disordered $\mathrm{C}_{5} \mathrm{H}_{2}$ and $\mathrm{C}^{\prime} \mathrm{H}_{2}$ moieties are displayed.

Compound 6 was prepared from $\delta$-valerolactam and dimethyl sulfate according to the procedure described in [34]. Compounds $\mathbf{3 a}, \mathbf{b}$ and 7 were prepared according to the procedures published in [12].

NMR spectra were measured using a Bruker AVANCE III spectrometer operating at $400.13\left({ }^{1} \mathrm{H}\right)$ and $100.62 \mathrm{MHz}\left({ }^{13} \mathrm{C}\right)$. Some spectra were also measured using a Bruker Avance 500 spectrometer operating at $500.13\left({ }^{1} \mathrm{H}\right)$ and $125.77 \mathrm{MHz}\left({ }^{13} \mathrm{C}\right)$. All the pulse sequences were taken from the Bruker software library. Proton spectra measured in $\mathrm{CDCl}_{3}$ were calibrated based on internal TMS $(\delta=0.00)$ and (in DMSO- $d_{6}$ ) based on the middle signal of the solvent multiplet $(\delta=2.55)$. Carbon NMR spectra were calibrated on the middle signal of the solvent multiplet $\left(\delta=77.23\left(\mathrm{CDCl}_{3}\right)\right.$ and $\left.39.60\left(\mathrm{DMSO}_{6} d_{6}\right)\right)$.

Elemental analyses were performed on a Flash 2000 CHNS Elemental Analyzer. Melting points were measured on a Kofler hot-stage microscope Boetius PHMK 80/2644 and were not corrected. MALDI HRMS were measured using a MALDI LTQ Orbitrap XL (Thermo Fisher Scientific) with DCTB as the matrix dissolved in acetonitrile. The crystal data of all the compounds were collected at room temperature using a Nonius 
Kappa CCD diffractometer with graphite monochromated $\mathrm{Mo} \mathrm{K} \alpha$ radiation. The data sets were integrated with the DenzoSMN package [35] and corrected for Lorentz, polarization and absorption effects (SORTAV) [36]. The structures were solved by direct methods using the SIR97 [37] system of programs and refined anisotropically by using full-matrix least-squares for all non-hydrogen atoms and hydrogen atoms included on their calculated positions, riding on their carrier atoms; except the $\mathrm{N}-\mathrm{H}$ hydrogens forming intramolecular hydrogen bonds, which were refined isotropically. In the structure $\mathbf{5 m}$ an ill-defined region of residual electron density was found. For this reason the program SQUEEZE was used to cancel out the effects of the undetermined disordered solvent. SQUEEZE is a part of the PLATON system of programs. All calculations were performed by using SHELXL-97 [38], PARST [39] and PLATON [40] implemented in WINGX [41] system of programs. Crystallographic data (excluding structure factors) have been deposited at the Cambridge Crystallographic Data Centre and allocated the deposition numbers CCDC 928078-928086. These data can be obtained free of charge via http://www.ccdc.cam.ac.uk/conts/ retrieving.html or on application to CCDC, Union Road, Cambridge, CB2 1EZ, UK [fax: (+44)1223-336033, e-mail: deposit@ccdc.cam.ac.uk].

\section{Typical procedure for the synthesis of com- pounds 4}

Enaminone 3a $(5 \mathrm{mmol})$ and $\mathrm{AcONa}(5 \mathrm{mmol})$ were dissolved in cold $\left(5^{\circ} \mathrm{C}\right)$ methanol. A saturated methanolic solution of 4-methylbenzenediazonium tetrafluoroborate $(5 \mathrm{mmol})$ was added dropwise over 30 minutes. The mixture was then stirred at ambient temperature for $24 \mathrm{~h}$. The solvent was evaporated in vacuo, and the crude product was dissolved in dichloromethane and subjected to flash chromatography on silica gel. Subsequent crystallization from $n$-hexane/ethanol afforded the pure products.

1-[2-(4-Methylphenyl)diazen-1-yl]-1-(piperidin-2ylidene)propan-2-one (4a, $\left.R=M e, A r^{1}=4-M e P h\right)$ yield $89 \%$, yellow crystals, mp $92-93{ }^{\circ} \mathrm{C} ;{ }^{1} \mathrm{H}$ NMR $(400 \mathrm{MHz}$, $\left.\mathrm{CDCl}_{3}\right) \delta 15.18(\mathrm{br} \mathrm{s}, 1 \mathrm{H}), 7.42-7.41$ (br m, 2H), 7.16-7.14 (br $\mathrm{m}, 2 \mathrm{H}), 3.46$ (br s, 2H), 3.08-3.06 (m, 2H), 2.50 (s, 3H), 2.33 (s, 3H), 1.71-1.73 (m, 4H) ppm; ${ }^{13} \mathrm{C}$ NMR (101 MHz, $\left.\mathrm{CDCl}_{3}\right)$ 197.7, 162.5, 148.5, 135.9, 129.5, 128.1, 119.2, 42.3, 28.2, 28.0, 21.0, 20.7, 18.6 ppm; Anal. calcd for $\mathrm{C}_{15} \mathrm{H}_{19} \mathrm{~N}_{3} \mathrm{O}$ : C, 70.01; $\mathrm{H}$, 7.44; N, 16.33; found: C, 69.87; H,7.40; N, 16.53.

\section{Typical procedures for the synthesis of pyrid- azinium salts 5}

Method A: Solid 4-nitrobenzenediazonium tetrafluoroborate $(5 \mathrm{mmol})$ was added in one portion into a cold $\left(5^{\circ} \mathrm{C}\right)$ mixture of enaminone 3a $(5 \mathrm{mmol})$ and sodium acetate $(5 \mathrm{mmol})$ in dichloromethane $(50 \mathrm{~mL})$. After the diazonium salt had been consumed (negative test on chromotropic acid), an equivalent of 4-diethylaminobenzenediazonium tetrafluoroborate ( $5 \mathrm{mmol}$ ) was immediately added. The reaction mixture was then stirred at ambient temperature for 4 days. Sodium acetate was removed by suction, and the filtrate was evaporated to dryness in vacuo. The residue was dissolved in methanol/chloroform (1:10) and subjected to flash chromatography on silica gel. Subsequent crystallization from methanol afforded the desired product.

Method B: The procedure is analogous to method A, only methanol was used as the solvent and the diazonium salts were added dropwise (as saturated methanolic solutions) into the reaction mixture. The second equivalent of the diazonium salt was added after the consumption of the first one (negative test on chromotropic acid). The solvent was then evaporated in vacuo and the crude was purified by flash chromatography and crystallization.

Method C: Saturated methanolic solution of 4-diethylaminobenzenediazonium tetrafluoroborate $(5 \mathrm{mmol})$ was added dropwise into the cold $\left(5^{\circ} \mathrm{C}\right)$ methanolic solution $(5 \mathrm{mmol}, 20 \mathrm{~mL})$ of azo compound $4 \mathrm{e}$ (prepared according to the abovementioned procedure) over 30 minutes. The reaction mixture was stirred for 4 days at room temperature. The solvent was then evaporated in vacuo. The residue was dissolved in methanol/chloroform (1:10) and subjected to flash chromatography on silica gel. Subsequent crystallization from methanol afforded the desired product.

2-(4-(Diethylamino)phenyl)-4-(4-nitrophenyldiazenyl)-3methyl-5,6,7,8-tetrahydropyrido[3,2-c]pyridazin-2-ium tetrafluoroborate (5f) Yields: A: 16\%, B: 85\%, C : 85\%, red crystals, mp $150-152{ }^{\circ} \mathrm{C} ;{ }^{1} \mathrm{H}$ NMR (400 MHz, DMSO- $d_{6}$ ) $\delta 11.39$ (br s, $1 \mathrm{H}), 8.48-8.45(\mathrm{~m}, 2 \mathrm{H}), 8.36-8.34(\mathrm{~m}, 2 \mathrm{H})$, $7.43-7.41(\mathrm{~m}, 2 \mathrm{H}), 6.85-6.83(\mathrm{~m}, 2 \mathrm{H}), 3.43$ (q, $J=7.0 \mathrm{~Hz}, 4 \mathrm{H})$, 3.08-3.05 (m, 2H), $2.86(\mathrm{~s}, 3 \mathrm{H}), 2.17-2.11(\mathrm{~m}, 2 \mathrm{H}), 1.15$ (t, $J=$ $7.0 \mathrm{~Hz}, 6 \mathrm{H}) ;{ }^{13} \mathrm{C}$ NMR (101 MHz, DMSO- $\left.d_{6}\right): 158.6,155.0$, 151.4, 148.8, 148.3, 137.1, 129.6, 126.8, 125.1, 124.0, 111.0, $43.9,42.2,27.6,18.2,17.0,12.3$; Anal. calcd for $\mathrm{C}_{24} \mathrm{H}_{28} \mathrm{BF}_{4} \mathrm{~N}_{7} \mathrm{O}_{2}$ : C, 54.05; H, 5.29; N, 18.38; found: C, 54.01; $\mathrm{H}, 5.45 ; \mathrm{N}, 18.10$.

\section{Supporting Information}

\section{Supporting Information File 1}

Experimental procedures, characterization data and X-ray parameters.

[http://www.beilstein-journals.org/bjoc/content/ supplementary/1860-5397-9-166-S1.pdf] 


\section{Acknowledgements}

The authors thank the Ministry of Education, Youth and Sports of the Czech Republic for the institutional support.

\section{References}

1. Eicher, T.; Hauptmann, S.; Speicher, A. The Chemistry of Heterocycles, 2nd ed.; Wiley-VHC: Weinheim, Germany, 2003.

2. Lue, P.; Greenhill, J. V. Enaminones in Heterocyclic Synthesis. In Advances in Heterocyclic Chemistry; Katritzky, A. R., Ed.; Academic Press: San Diego, USA, 1996; Vol. 67, pp 209-343.

3. Negri, G.; Kascheres, C.; Kascheres, A. J. J. Heterocycl. Chem. 2004, 41, 461-491. doi:10.1002/jhet.5570410402

4. Stanovnik, B.; Svete, J. Chem. Rev. 2004, 104, 2433-2480. doi:10.1021/cr020093y

5. Stanovnik, B.; Grošelj, U. Dialkyl Acetone-1,3-Dicarboxylates and their Mono- and bis(Dimethylamino)methylidene Derivatives in the Synthesis of Heterocyclic Systems. In Advances in Heterocyclic Chemistry; Katritzky, A. R., Ed.; Academic Press: San Diego, USA, 2010; Vol. 100, pp 145-174.

6. Rudenko, D. A.; Shurov, S. N.; Stepanyan, Y. G. Chem. Heterocycl. Compd. 2011, 47, 661-683. doi:10.1007/s10593-011-0818-9

7. Pešková, M.; Šimůnek, P.; Bertolasi, V.; Macháček, V.; Lyčka, A. Organometallics 2006, 25, 2025-2030. doi:10.1021/om051078x

8. Šimůnek, P.; Svobodová, M.; Bertolasi, V.; Macháček, V. Synthesis 2008, 1761-1766. doi:10.1055/s-2008-1067042

9. Svobodová, M.; Bárta, J.; Šimůnek, P.; Bertolasi, V.; Macháček, V. J. Organomet. Chem. 2009, 46, 63-71. doi:10.1016/j.jorganchem.2008.10.004

10. Šimůnek, P.; Svobodová, M.; Macháček, V. J. Heterocycl. Chem. 2009 , 46, 650-655. doi:10.1002/jhet.127

11. Šimůnek, P.; Macháček, V.; Svobodová, M.; Růžička, A. J. Heterocycl. Chem. 2011, 48, 780-786. doi:10.1002/jhet.579

12. Josefík, F.; Svobodová, M.; Bertolasi, V.; Šimůnek, P.; Macháček, V.; Almonasy, N.; Černošková, E. J. Organomet. Chem. 2012, 699, 75-81. doi:10.1016/j.jorganchem.2011.11.004

13. Svobodová, M.; Šimůnek, P.; Macháček, V.; Štruncová, L.; Růžička, A. Tetrahedron 2012, 68, 2052-2060. doi:10.1016/j.tet.2011.12.082

14. Šimůnek, P.; Pešková, M.; Bertolasi, V.; Lyčka, A.; Macháček, V. Eur. J. Org. Chem. 2004, 5055-5063. doi:10.1002/ejoc.200400287

15. Šimůnek, P.; Pešková, M.; Bertolasi, V.; Macháček, V.; Lyčka, A. Tetrahedron 2005, 61, 8130-8137. doi:10.1016/j.tet.2005.06.044

16. Fahmy, S. M.; Abed, N. M.; Mohareb, R. M.; Elnagdi, M. H. Synthesis 1982, 490-493. doi:10.1055/s-1982-29850

17. Mohamed, M. H.; Ibrahim, N. S.; Elnagdi, M. H. Heterocycles 1987, 26, 899-902. doi:10.3987/R-1987-04-0899

18. Ibrahim, N. S.; Abdel Galil, F. M.; Abdel-Motaleb, R. M.; Elnagdi, M. H. Heterocycles 1986, 24, 1219-1222. doi:10.3987/R-1986-05-1219

19. Hafez, E. A.; Khalifa, M. A. E.; Guda, S. K. A.; Elnagdi, M. H. Z. Naturforsch. 1980, 35b, 485-489.

20. Ibrahim, N. S.; Abdel Galil, F. M.; Abdel-Motaleb, R. M.; Elnagdi, M. H. Bull. Chem. Soc. Jpn. 1987, 60, 4486-4488. doi:10.1246/bcsj.60.4486

21. Elnagdi, M. H.; Sadek, K. U.; Taha, N. M.; Yassin, Y. M. Collect. Czech. Chem. Commun. 1990, 55, 734-744. doi:10.1135/cccc19900734

22. Ghozlan, S. A. S.; Mohamed, M. H.; Fakhr, Y.; Elnagdi, M. H. Liebigs Ann. Chem. 1990, 3, 293-296. doi:10.1002/jlac.199019900153

23. Ibrahim, N. S.; Mohamed, M. H.; Mahfouz, Y.; Elnagdi, M. H. J. Prakt. Chem. 1989, 331, 375-379. doi:10.1002/prac.19893310303
24. Mittelbach, M.; Wagner, U.; Kratky, C. Liebigs Ann. Chem. 1987, 10, 889-892. doi:10.1002/jlac.198719870844

25. Pahovnik, D.; Uršič, U.; Grošelj, U.; Meden, A.; Svete, J.; Stanovnik, B. Z. Naturforsch. 2008, 63b, 407-414.

26. Elnagdi, M. H.; Al-Awadi, N. A.; Abdelhamid, I. A. Recent Developments in Pyridazine and Condensed Pyridazine Synthesis. In Advances in Heterocyclic Chemistry; Katritzky, A. R., Ed.; Academic Press: San Diego, USA, 2009; Vol. 97, pp 1-43.

27. Riyadh, S. M.; Abdelhamid, I. A.; Ibrahim, H. M.; Al-Matar, H. M.; Elnagdi, M. H. Heterocycles 2007, 71, 2545-2586. doi:10.1016/S0385-5414(07)00060-3

28. Alnajjar, A.; Abdelkhalik, M. M.; Al-Enezi, A.; Elnagdi, M. H. Molecules 2009, 14, 68-77. doi:10.3390/molecules14010068

29. Macháček, V.; Čegan, A.; Halama, A.; Rožňavská, O.; Štěrba, V. Collect. Czech. Chem. Commun. 1995, 60, 1367-1379. doi:10.1135/cccc19951367

30. Šimůnek, P.; Lyčka, A.; Macháček, V. Eur. J. Org. Chem. 2002, 2764-2769. doi:10.1002/1099-0690(200208)2002:16<2764::AID-EJOC2764>3.0.C O;2-B

31. Šimůnek, P.; Bertolasi, V.; Lyčka, A.; Macháček, V. Org. Biomol. Chem. 2003, 1, 3250-3256. doi:10.1039/B303206J 32. Šimůnek, P.; Bertolasi, V.; Macháček, V. Eur. J. Org. Chem., in press. 33. Burnett, M. N.; Johnson, C. K. ORTEP III, Report ORNL-6895, Oak Ridge National Laboratory, Oak Ridge, TN, 1996.

34. Schann, S.; Bruban, V.; Pompermayer, K.; Feldman, J.; Pfeiffer, B.; Renard, P.; Schalbert, E.; Bousquet, P.; Ehrhardt, J.-D. J. Med. Chem 2001, 44, 1588-1593. doi:10.1021/jm001111b

35. Otwinowski, Z.; Minor, W. In Methods in Enzymology; Carter, C. W.; Sweets, R. M., Eds.; Academic Press: London, U.K., 1997; Vol. 276, Part A, pp 307-326.

36. Blessing, R. H. Acta Crystallogr., Sect. A 1995, 51, 33-38. doi:10.1107/S0108767394005726

37. Altomare, A.; Burla, M. C.; Camalli, M.; Cascarano, G. L.; Giacovazzo, C.; Guagliardi, A.; Moliterni, A. G. G.; Polidori, G.; Spagna, R. J. Appl. Crystallogr. 1999, 32, 115-119. doi:10.1107/S0021889898007717

38. Sheldrick, G. M. SHELX-97, University of Göttingen, Germany, 1997.

39. Nardelli, M. J. Appl. Crystallogr. 1995, 28, 659. doi:10.1107/S0021889895007138

40. Spek, A. L. Acta Crystallogr., Sect. D 2009, 65, 148-155. doi:10.1107/S090744490804362X

41. Farrugia, L. J. J. Appl. Crystallogr. 1999, 32, 837-838. doi:10.1107/S0021889899006020 


\section{License and Terms}

This is an Open Access article under the terms of the Creative Commons Attribution License

(http://creativecommons.org/licenses/by/2.0), which permits unrestricted use, distribution, and reproduction in any medium, provided the original work is properly cited.

The license is subject to the Beilstein Journal of Organic Chemistry terms and conditions:

(http://www.beilstein-journals.org/bjoc)

The definitive version of this article is the electronic one which can be found at:

doi:10.3762/bjoc. 9.166 